\title{
Larvicidal and Antifeedant Activity of Some Plants Extracts Against the Larvae of Helicoverpa Armigera (Hubner)
}

\author{
${ }^{1}$ G.Ravi, ${ }^{2}$ G.Sundararajan* \\ Asst. professor in Botany, Govt.Arts College, Dharmapuri-5, Tamil nadu, India
}

\begin{abstract}
In the present study, selected some plants, namely, Andrographis paniculata Ness., Cardiospermum halicacabum L., Cassia tora L., Catharanthus roseus L (G) Don., Datura metal L., Eupatorium riparium and Mikania micarantha were screened for their larvicidal and antifeedant activity against the larvae of Helicoverpa armigera (Hubner) under laboratory conditions. The crude extracts of all the selected plants demonstrated a dose dependent increase in bioactivity. However the bioactivity of four plants namely, A.paniculata, Cassia tora L., C.halicacabum L., and Datura metal L. was significantly higher $(\mathrm{p} \leq 0.05)$ than the control and extracts of C.roseus, E. riparium and M.micarantha. Methanol extract of A.paniculata caused highest oral toxicity with larval mortality ranging between $29.00 \%$ and $58.22 \%$ across the test concentration $(0.2 \%, 0.4 \%$ and $1 \% \mathrm{w} / \mathrm{v})$ while extract of C.tora L., demonstrated the highest feeding deterrence with reduction in larval feeding by 59.92\% and $76.61 \%$ at $0.2 \%$ and $0.4 \%$ respectively. Crude extract of C.halicacabum L., leaves demonstrated high oral toxicity and feeding deterrence while extract of D.metel showed moderate level of oral toxicity as well as feeding deterrence at the highest tested concentration. Thus it may be concluded that four out of the selected plants possess insecticidal property and can be further investigated for the development of a potent natural botanical insecticide.
\end{abstract}

Keywords: Plant extract, oral toxicity, antifeedant activity, Helicoverpa armigera.

\section{Introduction}

Helicoverpa armigera (Hubner) (Lepidoptera: Noctuidae) is a polyphagous migratory noctuid which is widespread in Asia (Lammers and Macleod, 2007). It is known to cause serious damage to hundreds of economically important crops all over the world (Setiawati et al., 2000; Fakrudin et al., 2004). In India it is reported to be feeding on 182 plant species across 47 families (Manjunath et al., 1985) and causes an annual loss of about Rs. 2,000 crores (Ignacimuthu and Jayaraj,2003). Fifty percent of all insecticides used in India and China are to control $H$. armigera alone (Lammers and Macleod, 2007) but the continuous and indiscriminate use of insecticides over the years has resulted in the $H$. armigera developing resistance to certain molecules belonging to different classes of insecticides in various parts of the world (Chaturvedi, 2007; Yang et al., 2013).Thus alternatives to the synthetic pesticides are being sought.

The search for alternatives to synthetic pesticides has focused the interest of the pest managers on natural plant derived pest control agents. Plant-based pesticides or botanicals have many advantages: firstly, they have multifarious control mechanisms against pests (Sivagnaname and Kalyanasundaram, 2004) which reduces the possibility of the development of resistance in pests (Liu et al., 2000); secondly, they are target-specific and hence not harmful to humans and beneficial insects; and lastly, they are not persistent in nature and hence environment friendly (Shaalan, 2005).

In the present investigation an attempt has been made to screen widely distributed plants, for their insecticidal activity against the larvae of $H$. armigera, which has been reported as a major pest of tomato and chickpea in India (Thakur et al., 2006). The effect of many different plants and their extracts on H. armigera has been studied by several authors (Sahayaraj, 1998; Sundararajan and Kumuthakalavalli 2017; Koul et al., 2002; Kathuria and Kaushik, 2005; Ramya et al., 2018; Wambua et al., 2011; Jeyashankar et al., 2012; Arivoli and Tennyson, 2013). While 
extracts of certain plants such as Ocimum basilicum, Gynandropsis gynandra, Acorus calamus, Lantana camara, and Toddalia asiatica demonstrated larvicidal effect on $H$. armigera (Pandey et al., 1983; Sundararajan and Kumuthakalavalli, 2017), others such as neem seed kernel extract were seen to have indirect effects such as causing larval-pupal intermediaries and abnormal adults (Jotwani and Srivastava, 1984) and feeding deterrency (Hongo and Karel, 1986). Majority of the plants tested against different larval instars of $H$. armigera have been reported to demonstrate antifeedant properties (Sahayaraj, 1998; Koul et al., 2002; Kathuria and Kaushik, 2005; Ramya et al., 2018; Wambua et al., 2011; Jeyashankar et al., 2012; Arivoli and Tennyson, 2013).

Although extensive research has been conducted on the effect of different plant extracts on $H$. armigera, there is limited literature available on the efficacy of plants such as Andrographis paniculata Ness., Cardiospermum halicacabum L., Cassia tora L., Catharanthus roseus L (G) Don., Datura metal L., Eupatorium riparium and Mikania micarantha which have a wide distribution in the study area of Tamil nadu and find application in medicinal practices of the local rural population (Neogi et al., 1989; Chhetri, 2008; Hynniewta and Kumar, 2008; Kayang et al., 2008; Sinha et al., 2008; Sohkhlet, 2014). The present study is aimed at determining the oral toxicity and antifeedant activity of the above mentioned plants against the larvae of H. armigera (Hubner).

\section{Materials and Methods}

\section{Collection of Plants}

The selected plants for this study were collected from in and around Dharmapuri district in Tamil Nadu. The selection of the plants was based on their local abundance, insecticidal properties and uses in traditional practices by the rural people of the state (Table 1). The samples were generally collected during the flowering and fruiting stage of the plants. All the selected plant species were identified with the help of volumes of Flora of the Madras Presidency (Gamble 1980) and Flora of the Tamil Nadu Karnatic (Matthew 1983).

Table 1: Evaluation of selected plants and the plant parts used for the study.

\begin{tabular}{|l|l|l|}
\hline Plant name & Common name & Plant parts used \\
\hline A.paniculata (Burm.f.) Ness., & Siriyanankai & Whole plant \\
\hline C.halicacabum L., & Mudakkaruthan & Leaves \\
\hline C.tora (L.) Roxb. & Thagarai & Leaves \\
\hline C.roseus (L.)G Don. & Nithyakalyani & Whole plant \\
\hline D. metel L, & Oomathai & Leaves \\
\hline E. riparium Regel & Snakeroots & Leaves \\
\hline M.micarantha Kunth & American rope & Aerial part \\
\hline
\end{tabular}

\section{Preparation of Plant Extracts}

The plants were brought to the laboratory immediately after collection and washed with tap water thoroughly followed by a final rinse with dechlorinated water, following which, they were shade dried at room temperature $\left(27 \pm 1^{\circ} \mathrm{C}\right)$ for $48-72$ hours, depending on the plant. The dried plants were ground to coarse powder using an electric blender. The crude extracts were prepared using standard protocol (Harborne, 1998; Houghton and Raman, 1998; Kathuria and Kaushik, 2005; Handa et al.,2008; Deepa and Remadevi, 2011). For the preparation of extracts, $100 \mathrm{gm}$ of each of the plant powders was extracted with 1 litre methanol using a Soxhlet apparatus for 48 hours. Prior to extraction with methanol, the plant material was defatted with petroleum ether. The extracts were taken to dryness under reduced pressure using a rotary-vacuum evaporator and stored in airtight screw capped borosil containers for future use. Prior to performance of a bioassay, a standard stock solution of $1 \% \mathrm{w} / \mathrm{v}$ concentration was prepared by dissolving $1 \mathrm{~g}$ of the extract in $10 \mathrm{ml}$ acetone and volume was made up to $100 \mathrm{ml}$ by adding deionized water. From the stock 
solution, $\quad 0.2 \%, \quad 0.4 \%, 0.6,0.8 \%$ and $1 \% \mathrm{w} / \mathrm{v}$ concentration was prepared for ingestion toxicity test and $0.2 \%, 0.4 \%$ and $1.0 \% \mathrm{w} / \mathrm{v}$ concentration for feeding deterrence test.

\section{Test Organism}

A laboratory culture of $H$. armigera larvae was maintained on a chickpea based semi-synthetic diet as suggested by Singh and Rembold (1992) under laboratory conditions $\left(27 \pm 1^{\circ} \mathrm{C}, 75 \pm 1 \%\right.$ R.H., and photoperiod of $12 \mathrm{~L}: 12 \mathrm{D})$. For the initial establishment of the colony in the laboratory, different instars of H.armigera larvae were collected from tomato crops grown in tomato field. The collected larvae were maintained on tomato leaves and fruits under laboratory conditions $\left(27 \pm 1^{\circ} \mathrm{C}, 75 \pm 1 \%\right.$ R.H. and photoperiod of $12 \mathrm{~L}: 12 \mathrm{D}$ ) in individual containers to prevent cannibalism and contamination until pupation. Pupae were transferred to clean containers with sterilized filter paper to facilitate moth emergence. Upon adult emergence, the male and female moths were paired and two pairs were released into individual mating chambers $(2.5 \times 1.5$ feet). The adults were fed on a diet of $1 \%$ honey solution and provided with cotton strips as oviposition medium (Kaushik and Kathuria, 2004). From the first generation onwards, the laboratory colony was maintained on a chickpea based semisynthetic diet. From the cultures, newly molted instar larvae were used for the bioassays.

\section{Bioassay Studies}

The larvicidal activity of plants was studied by oral application of the extracts through leaf dip method (Sundararajan and Kumuthakalavalli, 2017; Ramya et al., 2018). Freshly collected tomato leaves were individually dipped in the three different concentrations $(0.2 \%, 0.4 \%$ and $1 \% \mathrm{w} / \mathrm{v})$ of each of the extracts and air dried. A single treated leaf was kept in a petri plate lined with moist filter paper and a single six hour starved instar $H$. armigera larvae was introduced into the petri plate. Leaves treated with acetone were used as control. Larval mortality was recorded after 24 hours of exposure. A total of 10 larvae were individually exposed to each treatment and each treatment was replicated thrice. The total number of subjects per treatment was 30 larvae. The mortality data were represented as corrected mortality using Abbott's formula (Abbot, 1925).

\section{Feeding Deterrence Bioassay}

The antifeedant activity of crude extracts was assayed using leaf disc method (Sundararajan and Kumuthakalavalli, 2017). Discs of size $2.5 \mathrm{~cm}^{2}$ were punched from freshly collected tomato leaves and treated on each side with $10 \mu \mathrm{l}$ of the test solution emulsified with $0.1 \%$ Triton X-100. The extracts were tested at three different concentrations $0.2 \%, 0.4 \%$ and $0.1 \%$ w/v. Leaf discs treated with acetone solution and emulsifier $(0.1 \%)$ were used as control. The leaf discs were air dried and arranged in a petri plate with one treated and one control leaf disc per plate. A treated instar larva of $H$. armigera was then introduced at the center of the petri plate, such that it was equidistant from the treated and the control discs. The experiment was thus conducted with one larva per petri plate with ten larvae per treatment and each treatment was replicated three times. After six hours, the leaf discs were removed and the area consumed by the larvae was measured using a graph sheet method. The feeding deterrence index was calculated by using the formula given by Bomford and Isman (1996):

$$
\begin{aligned}
& \text { C-T } \\
& \text { FDI = -------- X } 100
\end{aligned}
$$

Where, $\mathrm{C}=$ area of consumption in the control; $\mathrm{T}=$ area of consumption in the treatment.

\section{Data Analysis}

The data obtained from the two bioassays were subjected to arcsine transformation prior to statistical analysis. The transformed data were then statistically analysed by one-way ANOVA. Separation of means and comparison between the different treatments was performed by Tukey's test at $\mathrm{P} \leq$ 0.05 . SPSS version 20 was used for the analysis. 


\section{Results}

\section{Toxicity Bioassay}

The larvicidal activity of methanolic extract of the selected plant species is presented in Table 2 . All the plants demonstrated a dose dependent increase in oral toxicity, with percentage mortality of the instar larvae of $H$. armigera being highest at test concentration of $1 \% \mathrm{w} / \mathrm{v}$. When tested at the concentration of $0.2 \%$, methanol extract of all the plants demonstrated an average mortality of $18.64 \%$ which was statistically similar $(\mathrm{p}>0.05)$ to the mortality rate of the larvae in the control. However, at concentration of $0.4 \%$ and $1 \% \mathrm{w} / \mathrm{v}$, the crude extracts of A.paniculata, C.tora and C.roseus caused significantly higher mortality $(\mathrm{p} \leq 0.000)$ than the control. The larvicidal activity demonstrated by the extract of A.paniculata against $H$. armigera, was the highest amongst all the selected plants with percent corrected mortality ranging from $29.77 \%$ to $78.22 \%$ across the test concentration. Its larvicidal activity was significantly higher than the control and the other plants $(\mathrm{p} \leq 0.05)$ except C.tora $(\mathrm{p}=0.672)$ and D.metel $(\mathrm{p}=0.315)$. The methanol extract of the leaves of C.tora demonstrated the second highest oral toxicity against the larvae of $\mathrm{H}$. armigera, with corrected larval mortality ranging between $21.61 \%$ and $52.23 \%$ across the test concentration. Of the remaining plants, extract of D.metel caused $35.11 \%$ larval mortality at the highest concentration of $1 \% \mathrm{w} / \mathrm{v}$ and it was significantly higher $(\mathrm{p}=0.014)$ than the larval mortality in control, thereby making it the third best plant after A.paniculata and C.tora in terms of oral toxicity against the larvae of $H$. armigera. However, it is to be noted that the synthetic insecticide, endosulfan $10 \%$ EC, which was used as control in this bioassay, caused $100 \%$ larval mortality within 24 hours of exposure and its activity was significantly higher $(\mathrm{p} \leq 0.000)$ than the activity of the plant extracts.

\section{Feeding Deterrence Bioassay}

The antifeedant activity of crude extracts of the selected plants was studied at three different concentrations. The feeding deterrence activity of the plants was assessed on the basis of the feeding deterrence index (FDI). Higher feeding deterrence index indicates lower feeding by the test organism. All the plants demonstrated dose dependent increase in feeding deterrence but irrespective of the test concentration of the plant extracts, the antifeedance index of the control was significantly lower $(\mathrm{p} \leq 0.0001)$ in comparison to that of the plants (Table 3). Of the plants, the crude extract of C.roseus demonstrated the highest antifeedant activity, causing $56.20 \%$ to $72.21 \%$ reduction in feeding by the larvae of $H$. armigera, across the test concentration and thus its FDI was significantly higher $(\mathrm{p} \leq 0.05)$ than the other plants. Apart from C.roseus, crude extract of C.tora, D.metal and A.paniculata also caused high feeding deterrence, which was significantly higher than the remaining plants with $\mathrm{p} \leq 0.05$. While the FDI on exposure to C.tora extract was $22.12 \%$ to $52.72 \%$ across test concentrations, D.metel extract reduced larval feeding by $36.07 \%$ to $49.39 \%$; and, A.paniculata extract reduced larval feeding in the range of $28.66 \%$ to $44.73 \%$ across the test concentrations.

Table 2: The larvicidal activity of the crude extracts of the selected plants against the larvae of Helicoverpa armigera.

\begin{tabular}{|l|l|l|l|}
\hline \multicolumn{1}{|c|}{ Plant name } & \multicolumn{3}{|c|}{ Concentration of Extract(\% W/V) } \\
\hline & $\mathbf{0 . 2 \%}$ & $\mathbf{0 . 4 \%}$ & $\mathbf{1 . 0 \%}$ \\
\hline A. paniculata & $29.77 \pm 6.93^{\mathrm{b}}$ & $44.81 \pm 5.01^{\mathrm{b}}$ & $58.22 \pm 8.01^{\mathrm{b}}$ \\
\hline C.halicacabum & $13.7 \pm 5.48^{\mathrm{b}}$ & $13.70 \pm 5.48^{\mathrm{def}}$ & $24.07 \pm 5.25^{\mathrm{cd}}$ \\
\hline C.tora & $20.37 \pm 9.45^{\mathrm{b}}$ & $35.55 \pm 3.85^{\mathrm{bcd}}$ & $51.48 \pm 7.88^{\mathrm{b}}$ \\
\hline C.roseus & $13.33 \pm 5.77^{\mathrm{b}}$ & $20.00 \pm 10.00^{\mathrm{cde}}$ & $24.07 \pm 5.25^{\mathrm{cd}}$ \\
\hline D. metel & $20.37 \pm 9.45^{\mathrm{b}}$ & $34.44 \pm 5.09^{\mathrm{bc}}$ & $37.77 \pm 3.85^{\mathrm{bc}}$ \\
\hline E. riparium & $7.04 \pm 6.12^{\mathrm{b}}$ & $7.04 \pm 6.12^{\mathrm{ef}}$ & $13.33 \pm 5.77^{\mathrm{de}}$ \\
\hline M.micarantha & $7.50 \pm 6.61^{\mathrm{b}}$ & $7.87 \pm 6.85^{\mathrm{ef}}$ & $18.52 \pm 6.41^{\mathrm{d}}$ \\
\hline Control & ------------- & ------------------- & ---------------- \\
\hline
\end{tabular}


Mean \pm SD represents mean percent corrected mortality of 3 replicates of 10 individuals each. Within columns, Means followed by the same alphabet do not differ significantly at $5 \%$ level of significance using Tukey's test.

Table 3: the antifeedant activity of the selected plants extracts against the larvae of Helicoverpa armigera.

\begin{tabular}{|l|l|l|l|}
\hline \multicolumn{1}{|c|}{ Plant name } & \multicolumn{3}{|c|}{ Concentration of Extract(\% W/V) } \\
\hline & $\mathbf{0 . 2 \%}$ & $\mathbf{0 . 4 \%}$ & $\mathbf{1 . 0 \%}$ \\
\hline A. paniculata & $28.66 \pm 2.95^{\mathrm{de}}$ & $35.44 \pm 6.83^{\mathrm{ab}}$ & $44.73 \pm 8.55^{\mathrm{bc}}$ \\
\hline C.halicacabum & $12.67 \pm 1.44^{\mathrm{c}}$ & $12.42 \pm 6.51^{\mathrm{cd}}$ & $17.12 \pm 7.31^{\mathrm{d}}$ \\
\hline C.tora & $22.12 \pm 5.68^{\mathrm{c}}$ & $46.61 \pm 7.16^{\mathrm{a}}$ & $52.72 \pm 4.93^{\mathrm{ab}}$ \\
\hline C.roseus & $56.20 \pm 2.19^{\mathrm{a}}$ & $50.92 \pm 11.21^{\mathrm{a}}$ & $72.21 \pm 9.04^{\mathrm{a}}$ \\
\hline D. metel & $36.07 \pm 1.05^{\mathrm{b}}$ & $43.57 \pm 6.7^{\mathrm{a}}$ & $49.39 \pm 5.25^{\mathrm{b}}$ \\
\hline E. riparium & $12.83 \pm 0.83^{\mathrm{e}}$ & $15.8 \pm 9.85^{\mathrm{bc}}$ & $17.31 \pm 5.31^{\mathrm{d}}$ \\
\hline M. micarantha & $21.57 \pm 1.31^{\mathrm{cd}}$ & $23.99 \pm 6.03^{\mathrm{ab}}$ & $25.26 \pm 5.92^{\mathrm{cd}}$ \\
\hline Control & ------------- & ---------------- & ----------------- \\
\hline
\end{tabular}

Mean \pm SD represents mean percent feeding deterrence of 3 replicates of 10 individuals each. Within columns, means followed by the same alphabet do not differ significantly at $5 \%$ level of significance using Tukey's HSD test.

\section{Discussion}

The ingestion toxicity bioassay revealed that larvicidal activity of the crude methanolic extract of the plants was much lower than that of the synthetic insecticide, Endosulfan 10\% EC. However, four out of the selected plants caused significantly higher $(\mathrm{p} \leq 0.05)$ larval mortality as well as feeding deterrence in comparison to the solvent control indicating potent insecticidal activity against the notorious pest, $H$. armigera.

The results of the present study indicated that at higher concentrations, A.paniculata could act both as a potent oral toxicant and feeding deterrent against $H$. armigera larvae, and this result is in agreement with the findings of Prasad and Roy (2011), who had concluded from their histopathological study that extracts of A.paniculata could act as stomach poison in addition to some antifeedant activity against the larvae of $H$. armigera. In a study by Murugesan and co-workers (2012), it was reported that essential oil at a concentration range of 2500-10000 ppm caused 20-50\% larval mortality after 24 hours exposure against third instar larvae of teak defoliator, Hyblaea puera while in another study, aqueous crude extract of L. camara leaves at a concentration of $40 \%$ caused $100 \%$ mortality of fourth instar larvae of Spodoptera litura (Deshmukhe et al., 2011). Both these studies found that larvicidal activity of A.paniculata increased with increase in its concentration which corroborated with our present findings. Tennyson (2013), at a concentration of $1 \%$, the ethyl acetate crude extract of $L$. camara showed $25-50 \%$ antifeedance against third instar larvae of Spodoptera litura while the hexane and dichloromethane extracts showed $<25 \%$ antifeedance. Our study indicated higher activity of methanolic extract of A.paniculata, causing $40.74 \%$ feeding deterrence against fourth instar $H$. armigera larvae, at a much lower concentration of $0.4 \% \mathrm{w} / \mathrm{v}$. However, it may be noted that different test organisms were used in the investigations conducted by other authors and many studies have shown that even closely related insect species can show widely different susceptibilities to the same extract or compound (Isman, 1993), which could be one of the reasons for the variation between the outcome of the present study and the previous studies. 
The insecticidal activity of plants is attributed to the presence of various phytochemical groups (Kabaru and Gichia, 2001) and the occurrence of more than one major class of phytocompounds is responsible for the different modes of action of plant extracts against the target pests (Park et al.,2002; Lingathurai et al., 2011). All three groups of phytocompounds have been reported to affect herbivorous insect's growth and development either by feeding inhibition or through post-ingestive phenomena (Coley et al., 1985; Barbehenn et al., 2001; Hoffman-Campo et al., 2001; Lago et al., 2002; Treutter, 2006; Jadhav et al., 2012). In addition, extracts of L. camara and L. cubeba also tested positive for terpenoids. Terpenoids in plants can act mainly as antifeedant and growth disruptor and possess considerable toxicity toward insects (Kubo and Nakanishi,1978; Khalid et al., 1989). Saponins on the other hand are a class of phytochemicals which are reported to be insecticidal by many investigators (Marston and Hostettmann, 1985; Jeong et al., 2004; Sparg et al., 2004; McGaw et al., 2008). Thus, the insecticidal and antifeedant activity demonstrated by the methanol extracts of C.roseus, A.paniculata. C.tora and D.metel could be the result of composite effect of all these classes of phytocompounds.

However, the present study is a preliminary investigation which indicates that crude methanol extracts of the four plants possess insecticidal property. Future research has to be conducted with these plants to understand their exact mode of action/s as well as isolate and identify the bioactive compound/s responsible for the toxicity demonstrated towards the target pest.

\section{Conclusion}

From the present study it can be concluded that out of seven selected plants, four plants namely, Andrographis paniculata Ness., Cardiospermum halicacabum L., Cassia tora L., Catharanthus roseus $L(G)$ Don., Datura metal L., Eupatorium riparium and Mikania micarantha have demonstrated promising insecticidal activity against $H$. armigera larvae. Further research on the bioactivity of these commonly found plants can lead to the development of a cost effective, eco-friendly formulation for crop protection, which will be beneficial to farmers of states such as Tamilnadu where organic farming is being encouraged by the Central and the State governments.

\section{ACKNOWLEDGEMENT}

This research did not receive any specific grant from funding agencies in the public, commercial, or not for profit sectors.

\section{References}

[1.] Abbott, W. S. 1925. A method for computing the effectiveness of an insecticide. Journal of Economic Entomology, 18: 265-267.

[2.] Arivoli, S. And Tennyson, S. 2013. Antifeedant activity, developmental indices and morphogenetic variations of plant extracts against Spodoptera litura (Fab) (Lepidoptera: Noctuidae). Journal of Entomology and Zoology Studies, 1 (4): 87-90.

[3.] Barbehenn, R. V., Bumgarner, S. L., Roosen, E. F. and Martin, M. M. 2001. Antioxidant defenses in caterpillars: role of the ascorbate-recycling system in the midgut lumen. Journal of Insect Physiology, 47 (4-5): 349-357.

[4.] Bomford, M. K. and Isman, M. B. 1996. Desensitization of fifth instar Spodoptera litura to azadirachtin and neem. Entomologia Experimentalis et Applicata, 81: 301-313.

[5.] Chaturvedi, I. 2007. Status of insecticide resistance in the cotton bollworm, Helicoverpa armigera (Hubner). Journal of Central European Agriculture, 8 (2): 171-182.

[6.] Chhetri, R. 2008. Trends in ethnodomestication of some wild plants in Meghalaya, Northeast India. Indian Journal of Traditional Knowledge, 5 (3): 342-347.

[7.] Coley, P. D., Bryant, J. P. and Chapin, S. 1985. Resource availability and plant anti herbivore defence. Science, 230: 895-899.

[8.] Deepa, B and Remadevi, O. K. 2011. Insecticidal Activity of the Phytoextracts derived from different parts of the trees of Fabaceae family against Hyblaea puera Cramer (Lepidoptera: Hyblaeidae). Biological Forum, 3 (2): 1-8. 
[9.] Deka, M. K., Singh, K. and Handique, R. 1998. Antifeedant and repellent effects of pongam (Pongamia pinnata) and wild sage (Lantana camara) on tea mosquito bug (Helopeltis theivora). Indian Journal of Agricultural Science, 68: 274-276.

[10.] Deshmukhe, P. V., Hooli, A. A. and Holihosur, S. N. 2011. Effect of Lantana camara (L.) On growth, development and survival of tobacco caterpillar (Spodoptera litura Fabricius). Karnataka Journal of Agricultural Science, 24 (2): 137-139.

[11.] Fakrudin, B., Kumar, V., Krishnareddy, K., Patil, B. and Kuruvinashetti, M. 2004. Morphometric differences between pyrethroid resistant and susceptible populations of cotton bollworm, Helicoverpa armigera. Resistant Pest Management Newsletter, 13: 18-19.

[12.] Feng, X., Jiang, H., Zhang, Y., He, W. And Zhang, L. 2012. Insecticidal activities of ethanol extracts from thirty Chinese medicinal plants against Spodoptera exigua (Lepidoptera: Noctuidae). Journal of Medicinal Plants Research, 6 (7): 1263-1267.

[13.] Gamble, J. S. 1935. Flora of the presidency of madras, vol. 1. botanical survey of India, Calcutta, India. $\mathrm{Pp}$ 40-41.

[14.] Handa, S. S. 2008. An Overview of Extraction Techniques for Medicinal and Aromatic Plants, In: Handa, S. S., Khanuja, S. P. S., Longo, G. and Rakesh, D. D. (Eds.), Extraction Technologies for Medicinal and Aromatic Plants, International Centre for Science and High Technology, Trieste, pp. 22-30.

[15.] Harborne, J. B. 1998. Phytochemical Methods- A Guide to Modern Techniques of Plant Analysis. Chapman and Hall Publishers. London. pp. 1-32.

[16.] Hoffman-Campo, C. B., Harborne, J. B. and McCaffery, A. R. 2001. Preingestive and postingestive effects of soya bean extracts and rutin on Trichoplusia ni growth. Entomologia Experimentalis et Applicata,

a. 98: 181-194.

[17.] Hongo, H. and Karel, A. K. 1986. Effect of plant extract on insect pest of common beans. Zeitschrift Fur Angewandte Entomologie, 102: 164-169.

[18.] Houghton, P. J. and Raman, A. 1998. Laboratory Handbook for The Fractionation of Natural Extracts. Chapman and Hall Publishers. London

[19.] Hynniewta, S. R. and Kumar, Y. 2008. Herbal remedies among the Khasi traditional healers and village folks in Meghalaya. Indian Journal of Traditional Knowledge, 7 (4): 581-586.

[20.] Ignacimuthu, S. and Jayaraj, S. 2003. Ecofriendly approaches for sustainable pest management. Current Science, 84: 10-25.

[21.] Indofil. 2016. Indofil industries limited. Available on: business- area/agriculturalchemicals/insecticides/gem (Accessed on $2^{\text {nd }}$ May, 2016).

[22.] Isman, M. B. 1993. Growth inhibitory and antifeedant effects of azadirachtin on six noctuids of regional economic importance. Pesticide Science, 38: 57-63.

[23.] Jadhav, D. R., Mallikarjuna, N., Rathore, A. and Pokle, D. 2012. Effect of some flavonoids on survival and development of Helicoverpa armigera (Hbner) and Spodoptera litura (Fab) (Lepidoptera: Noctuidae). Asian Journal of Agricultural Sciences, 4 (4): 298-307.

[24.] Jeong, S. I., Kim, K. J., Choo, Y. K., Keum, K. M., Choi, B. K. and Jung, K. Y.2004. Phytolacca americana inhibits the high glucose-induced mesangial proliferation via suppressing extracellular matrix accumulation and TGF-b production. Phytomedicine, 11: 175-181.

[25.] Jeyasankar, A. 2012. Antifeedant, insecticidal and growth inhibitory activities of selected plant oil on black cutworm, Agrotis ipsilon (Hufnagel) (Lepidoptera: Noctucidae). Asian Pacific Journal of Tropical Diseases,

a. $2: 347-351$.

[26.] Jeyasankar, A., Premalatha, S. and Elumalai, K.2012. Biological activities of Solanum pseudocapsicum (Solanaceae) against cotton bollworm, Helicoverpa armigera Hubner and armyworm, Spodoptera litura Fabricius (Lepidotera: Noctuidae). Asian Pacific Journal of Tropical Biomedicine, 2 (12): 981-986.

[27.] Jiang, Z. L., Akhtar, Y., Bradbury, R., Zhang, X. and Isman, M. B. 2009. Comparative toxicity of essential oils of Litsea pungens and Litsea cubeba and blends of their major constituents 
against the cabbage looper, Trichoplusia ni. Journal of Agricultural and Food Chemistry, 57: 4833-4837.

[28.] Kabaru J.M. and Gichia L. 2001. Insecticidal activity of extracts derived from different parts of the mangrove tree Rhizophora mucronata (rhizophoraceae) Lam. against three anthropods. African Journal of Science and Technology (AJST). Science \& Engineering Series 2 (2): 44-49.

[29.] Kanis, L., Antonio, R., Antunes, É., Prophiro, J. and Silva, O. 2009. Larvicidal effect of dried leaf extracts from Pinus caribaea against Aedes aegypti (Linnaeus, 1762) (Diptera: Culicidae). Revista da Sociedade Brasileira de Medicina Tropical, 42 (4): 373-376.

[30.] Kathuria, V. and Kaushik, N. 2005. Feeding Inhibition of Helicoverpa armigera (Hubner) by Eucalyptus camaldulensis and Tylophora indica extracts. Insect Science, 12: 249-254.

[31.] Kayang, H., Kharbuli, B. and Syiem, D. 2008. Gaultheria fragrantissima Wall.-an untapped economic plants species of Meghalaya. Natural Product Radiance, 7 (5): 400.

[32.] Khalid, S. A., Duddeck, H. and Gonzalez- Sierra, M. 1989. Isolation and characterization of an antimalarial agent of the neem tree Azadirachta indica. Journal of Natural Products, 52: 922-926.

[33.] Ko, K., Juntarajumnong, W. and Chandrapatya, A. 2009. Repellency, fumigant and contact toxicities of Litsea cubeba (Lour.) Persoon against Sitophilus zeamais Motschulsky and Tribolium castaneum (Herbst). Kasetsart Journal, 43:56-63.

[34.] Koul, O., Kaur, H., Goomber, S. and Wahab, S., 2004. Bioefficacy and mode of action of rocaglamide from Aglaia elaeagnoidea (syn A. roxburghiana) against gram pod borer, Helicoverpa arm igera (Hubner). Journal of Applied Entomology, 128: 177-181.

[35.] Koul, O., Multani, J. S., Singh, G. and Wahab, S. 2002. Bioefficacy of Toosendanin from Melia dubia (syn. M. azedarach) against gram pod-borer Helicoverpa armigera (Hubner). Current Science, 83: 1387-1391.

[36.] Kubo, I. and Nakanishi, K. 1978. Some terrpenoid insect antifeedants from tropical plants-I. Proceedings of $4^{\text {th }}$ International Congress of Pesticide Chemistry, Zurich, Switzerland, p. 284.

[37.] Lago, J. H. G., Brochini, C. B. and Roque, N. F. 2002. Terpenoids from Guarea guidonia. Phytochemistry, 60: 333-338.

[38.] Lammers, J. W. and Macleod, A. 2007. Report of a pest risk analysis: Helicoverpa armigera (Hubner, 1808). European Union. Retrieved from https://secure.fera. defra.gov.uk/phiw/riskRegister/plant health/ documents/helicoverpa.pdf (Accessed on 13 Jun, 2013).

[39.] Lingathurai, S., Vendan,S. E, Paulraj, M. G. and Ignacimuthu, S. 2011. Antifeedant and larvicidal activities of Acalypha fruticosa Forssk. (Euphorbiaceae) against Plutella xylostella L. (Lepidoptera: Yponomeutidae) larvae. Journal of King Saud University a. (Science), 23: 11-16.

[40.] Liu, S., Shi, J., Cao, H., Jia, F., Liu, X. and Shi, G. 2000. Survey of pesticidal component in plant. In: Dianmo, L. (Ed.), Entomology in China in 21st Century, Proceedings of Conference of Chinese Entomological Society, Science \& Technique Press, Beijing, China. pp: 1098-1104.

[41.] Liu, Z., Goh, S. and Ho, S. 2007. Screening of Chinese medicinal herbs for bioactivity against Sitophilus zeamais Motschulsky and Tribolium castaneum (Herbst). Journal of Stored Products Research, 43 (3): 290-296.

[42.] Matthew, K.H. 1983. The flora of the Tamil Nadu Carnatic, the rapinat hes Boaium, St. Joseph's College, Tiruchirapalli. Vol.1-11l.

[43.] Manjunath, T., Bhatnagar, V., Pawar, C. and Sithanantham, S. 1985. Economic importance of Heliothis spp. in India and assessment of their natural enemies and host plants. Proceedings of the Workshop on Biological Control of Heliothis: Increasing the Effectiveness of Natural Enemies, New Delhi, p: 197-228.

[44.] Marston, A. and Hostettmann, K. 1985. Plant molluscicides. Phytochemistry, 2: 639-652. 
[45.] McCaffery, A. R. 1998. Resistance to insecticides in Heliothine lepidoptera: A Global View. Philosophical Transactions of the Royal Society B: Biological Sciences, 353 (1376): 1735-1750.

[46.] McGaw, L. J., Lall, N., Meyer, J. J. and Eloff, J. N. 2008. The potential of South African plants against mycobacterium infections. Journal of Ethnopharmacology, 119: 482-500.

[47.] Murugesan, N. and Murugesh, T. 2009. Bioefficacy of some plant products against brinjal fruit borer, Leucinodes orbonalis Guenee (Lepidoptera: Pyrallidae). Journal of Biopesticides, 2 (1):60-63.

[48.] Murugesan, S., Rajeshkannan, C., Suresh Babu, D., Sumathi, R. and Manivachakam, P. 2012. Identification insecticidal properties in common weed - Lantana camara Linn. by gas chromatography and mass spectrum (GC-MS-MS). Advances in Applied Science Research, 3 (5): 2754-2759.

[49.] Neogi, B., Prasad, M. N. V. and Rao, R. R. 1989.Ethnobotany of some weeds of Khasi and Garo Hills, Meghalaya, Northeastern India. Economic Botany, 43 (4): 471-479.

[50.] Nor Azah M. A. and Susiarti, S. 1999. Litsea cubeba (Lour.) Parson in essential oil plants. In: L. Oyen, P. A. and Dung, N. X. (Eds.), Plant Resources of South East Asia, Vol. 19, Backhuys Publishers., Leiden, pp: 123-126.

[51.] Ogendo, J. O., Belmain, S. R., Deng, A. L. and Walker, D. J. 2003. Comparison of toxic and repellent effects of Lantana camara L. with Tephrosia vogelii Hook. and a synthetic pesticide against Sitophilus zeamais Motschulsky (Coleoptera: Curculionidae) in stored maize grain. Insect Science Application, 23 (2): 127-135.

[52.] Palanimuthu, A., Kadarkarai, M., Anbazhagan, P. and Sujitha, R. 2014. Larvicidal, pupicidal and repellent activities of Gaultheria Oil (Plantae: Ericaceae) against the filarial vector, Culex quinquefasciatus (Insecta: Diptera: Culicidae). Journal of Entomology and Zoology Studies, 2 (4):290-294.

[53.] Park, S. B., Lee, E. S., Choi, S. W., Jeong, Y. C., Song, C. and Cho, Y. W. 2002. Insecticidal and acaricidal activity of piperonndine and piperoctadealidne derived from dried fruits of Piper longum L. Crop Protection, 21: 249-251.

[54.] Prasad, A. and Roy, S. 2011. Histoarchitechtural alterations in the midgut tissues of fourth instar larvae of grampod borer, Helicoverpa armigera (Hub) fed with leaf extract of plant, Lantana camara (L). International Journal of Pharmacy and Biological Sciences, 2 (4): B (613)-B (620).

[55.] Ramya, S., Rajasekaran, C., Sundararajan, G., Alaguchamy, N. and Jayakumararaj, R. 2018. Antifeedant activity of leaf aqueous extracts of selected medicinal plants on VI instar larva of Helicoverpa armigera (Hubner), Ethnobotanical Leaflets, 12: 938-943.

[56.] Ranyaphi, R. A., Mao, A. A. and Borthakur, S. K. 2012. Invitro plant regeneration of wintergreen (Gaultheria fragrantissima Wall.): assessment of multiple nutrient formulations and cytokinin types. Indian Journal of Biotechnology, 11: 197-204.

[57.] Sahayaraj, K. 1998. Antifeedant effect of some plant extracts on the Asian armyworm, Spodoptera litura (Fabricius). Current Science, 74: 523-525.

[58.] Senthilkumar, A. and Venkatesalu, V. 2012. Larvicidal potential of Acorus calamus L. essential oil against filarial vector mosquito Culex quinquefasciatus (Diptera: Culicidae). Asian Pacific Journal of Tropical Disease, 2 (4): 324-326.

[59.] Setiawati, W., Somantri, A. and Duriat, A. 2000. Effect of population density and infestation of Helicoverpa armigera Hubner on tomato yield loss and its control. Journal of Horticulture, 10: 112-120.

[60.] Shaalan, E., Canyon, D., Younes, M., Abdel- Wahab, H. and Mansour, A. 2005. A review of botanical phytochemicals with mosquitocidal potential. Environment International, 31: 1149-1166.

[61.] Singh, A. K. and Rembold, H. 1992. Maintenance of the cotton bollworm, Heliothis armigera Hubner (Lepidoptera: Noctuidae) in laboratory culture-I. Rearing on semi-synthetic diet. International Journal of Tropical Insect Science, 13: 333-338. 
[62.] Sinha. B., Dey, S. and Kalita, J. 2008. How the hill farmers control pests using locally available resources: Lessons from the upland areas of North East India. Available on SSRN: http://ssrn.com/abstract $=1303990$. doi:10.2139/ssrn.1303990 (Accessed on March $21^{\text {st }}$ 2012).

[63.] Sivagnaname, N., and Kalyanasundaram, M. 2004. Laboratory evaluation of methanolic extract of Atlantia monophylla (Family: Rutaceae) against immature stages of mosquitoes and non-target organisms. Memórias do Instituto Oswaldo Cruz, 99 (1): 115 118.

[64.] Sofowora A. 1993. Medicinal plants and Traditional Medicine in Africa. Spectrum Books Ltd, Ibadan, Nigeria. pp. 289.

[65.] Sohkhlet, M. 2014. Evaluation of traditional insect-pest management practices in agricultural crops of Khasi and Jaintia hills, Meghalaya. Ph. D. Dissertation, North Eastern Hill University, Shillong. 41 pp.

[66.] Sparg, S. G., Light, M. E. and Staden, J. V. 2004. Biological activities and distribution of plant saponins. Journal of thnopharmacology, 94: 219-243.

[67.] Sundararajan, G. and Kumuthakalavalli, R. 2017. Antifeedant activity of aqueous extract of Gnidia glauca Gilg. And Toddalia asiatica Lam. on the gram pod borer, Helicoverpa armigera (Hbn). Journal of Environmental Biology, 22 (1):11-14.

[68.] Thakur, N., Shylesha A. And Rao, R. 2006. Major insect pests of agri- orticultural crops and their management in north eastern hill region. In: Dwivedi, S. (Ed.), Integrated Pest Management and Biocontrol $1^{\text {st }}$ ed. Pointer Publ. Pvt. Ltd., New Delhi, pp: 196-99.

[69.] Trease, G. E. and Evans, W. C. 1989. Pharmacology $11^{\text {th }}$ ed., Bailliere Tindall Ltd., London, pp: 60-75.

[70.] Treutter, D. 2006. Significance of flavonoids in plant resistance: a review. Environmental Chemistry Letters, 4 (3): 147-157.

[71.] Wambua L. M., Deng A. L., Ogendo J. O., Owuoche J. and Bett P. K. 2011. Toxic, antifeedant and repellent activity of aqueous crude extracts of Tephrosia vogelii Hook on the larval stages of Helicoverpa armigera Hubner. Baraton Interdisciplinary Research Journal, 1: 19-29.

[72.] Yang, Y., Li, Y. and Wu, Y. 2013. Current status of insecticide resistance in Helicoverpa armigera after 15 years of Bt cotton planting in China. Journal of Economic Entomology, 106 (1): $375-8$. 